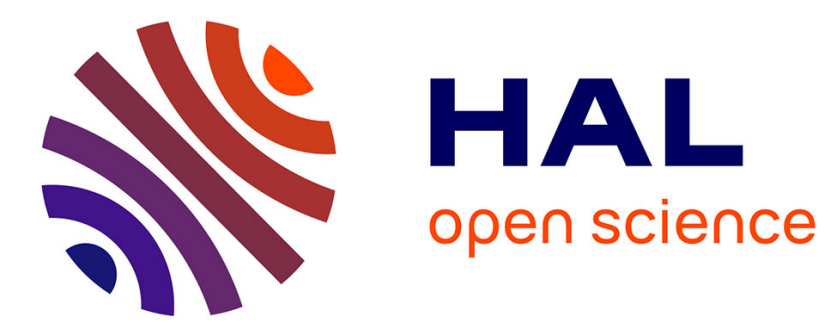

\title{
Persistent maternal depressive symptoms trajectories influence children's IQ: The EDEN mother-child cohort
}

Judith van Der Waerden, Jonathan Y. Bernard, Maria de Agostini, Marie-Josèphe Saurel-Cubizolles, Hugo Peyre, Barbara Heude, Maria Melchior

\section{- To cite this version:}

Judith van Der Waerden, Jonathan Y. Bernard, Maria de Agostini, Marie-Josèphe Saurel-Cubizolles, Hugo Peyre, et al.. Persistent maternal depressive symptoms trajectories influence children's IQ: The EDEN mother-child cohort. Depression and Anxiety, 2016, 10.1002/da.22552 . hal-01371956

\section{HAL Id: hal-01371956 https: / hal.sorbonne-universite.fr/hal-01371956}

Submitted on 26 Sep 2016

HAL is a multi-disciplinary open access archive for the deposit and dissemination of scientific research documents, whether they are published or not. The documents may come from teaching and research institutions in France or abroad, or from public or private research centers.
L'archive ouverte pluridisciplinaire HAL, est destinée au dépôt et à la diffusion de documents scientifiques de niveau recherche, publiés ou non, émanant des établissements d'enseignement et de recherche français ou étrangers, des laboratoires publics ou privés. 


\section{Persistent maternal depressive symptoms trajectories influence children's IQ: \\ The EDEN mother-child cohort}

Running head: Maternal depressive symptom trajectories and children's IQ

Judith van der Waerden, MSc PhD ${ }^{\mathrm{ab}^{*}}$, Jonathan Y. Bernard, $\mathrm{PhD}^{\mathrm{cd}}$, Maria De Agostini, $\mathrm{PhD}^{\mathrm{cd}}$,

Marie-Josèphe Saurel-Cubizolles, $\mathrm{PhD}{ }^{\text {be }}$, Hugo Peyre, $\mathrm{MD} \mathrm{PhD}{ }_{\mathrm{fg}}^{\mathrm{g}}$, Barbara Heude, $\mathrm{PhD}{ }^{\mathrm{cd}}$, Maria Melchior, $\mathrm{ScD}^{\mathrm{ab}}$ for The EDEN Mother-Child Cohort Study Group ${ }^{1}$

(a) INSERM UMR_S 1136, Pierre Louis Institute of Epidemiology and Public Health, Department of Social Epidemiology, F-75013 Paris, France

(b) Sorbonne Universités, UPMC Univ Paris 06, F-75005 Paris, France

(c) INSERM, UMR1153 Epidemiology and Biostatistics Sorbonne Paris Cité Center (CRESS),

Developmental Origins of Health and disease (ORCHAD) Team, Villejuif, F-94807 France;

(d) Paris Descartes University France

(e) INSERM, UMR_S 953, Epidemiological Research on Perinatal Health and Women's and

Children's Health, F-94807 Villejuif, France

(f) Laboratoire de Sciences Cognitives et Psycholinguistique (ENS, EHESS, CNRS), Ecole Normale Supérieure, PSL Research University, Paris, France.

(g) Hôpital Robert Debré, Service de Psychopathologie de l'Enfant et de l'Adolescent, APHP, Paris, France

${ }^{1}$ The EDEN Mother-Child Cohort Study Group includes I. Annesi-Maesano, J.Y. Bernard, J. Botton, M.A. Charles, P. Dargent-Molina, B. de Lauzon-Guillain, P. Ducimetière, M. de Agostini, B. Foliguet, A. Forhan, X. Fritel, A. Germa, V. Goua, R. Hankard, B. Heude, M. Kaminski, B. Larroque†, N. Lelong, J. Lepeule, G. Magnin, L. Marchand, C. Nabet, F. Pierre, R. Slama, M.J. Saurel-Cubizolles, M. Schweitzer, O. Thiebaugeorges. 


\section{* Corresponding author}

Judith van der Waerden

Pierre Louis Institute of Epidemiology and Public Health,

INSERM \& Sorbonne Universités UPMC

27 Rue de Chaligny

75571 Paris Cedex 12, France

Tel: $+33(0) 185560242$

Mail : judith.van-der-waerden@inserm.fr

Keywords: cognitive development; IQ; maternal depression trajectories; longitudinal cohort study

All authors have completed the coi disclosure form and declare no conflict of interest or financial disclosures related to this work. 


\begin{abstract}
Background This study assessed the association between timing and course of maternal depression from pregnancy onwards and children's cognitive development at ages 5 to 6 . Potential interaction effects with child sex and family socioeconomic status were explored.
\end{abstract}

Methods 1039 mother-child pairs from the French EDEN mother-child birth cohort were followed from 24-28 weeks of pregnancy onwards. Based on CESD and EPDS scores assessed at six time points, longitudinal maternal depressive symptom trajectories were calculated with a group-based semi-parametric method. Children's cognitive function was assessed at ages 5 to 6 by trained interviewers with the Wechsler Preschool and Primary Scale of Intelligence Third Edition (WPPSIIII), resulting in three composite scores: Verbal IQ (VIQ), Performance IQ (PIQ), and Full-Scale IQ (FSIQ).

Results Five trajectories of maternal symptoms of depression could be distinguished: no symptoms; persistent intermediate-level depressive symptoms; persistent high depressive symptoms; high symptoms in pregnancy only; and high symptoms in the child's preschool period only. Multiple linear regression analyses showed that, compared to children of mothers who were never depressed, children of mothers with persistent high-levels of depressive symptoms had reduced VIQ, PIQ and FSIQ scores. This association was moderated by the child's sex, boys appearing especially vulnerable in case of persistent maternal depression.

Conclusions Chronicity of maternal depression predicts children's cognitive development at school entry age, particularly in boys. As maternal mental health is an early modifiable influence on child development, addressing the treatment needs of depressed mothers may help reduce the associated burden on the next generation. 


\section{Introduction}

General cognitive ability in childhood, as measured by psychometric intelligence (IQ), is a strong predictor of many important outcomes across the lifespan, including later educational attainment, socioeconomic status and health ${ }^{[1]}$. Numerous studies have shown that the genetic and environmental influences on intelligence change from age to age, but that the rapid cognitive development that takes place during early childhood is to a large extent influenced by children's psychosocial environment ${ }^{[2]}$. Maternal depression is considered a risk factor for developmental difficulties, as mothers generally play an important part in the child's early environment and his/her learning experiences ${ }^{[3]}$. Children of depressed mothers show more problems in the cognitive, linguistic and psychomotor domains, as well as in terms of IQ and school readiness ${ }^{[4 ; 5]}$.

Depression timing, chronicity and severity vary considerably between women, but the heterogeneity of depressive illness and its differential effects on children's cognitive development have rarely been considered. The influence of maternal depressive symptoms on the young child's cognitive performance could vary as a function of timing in brain development and the duration of exposure to maternal depression ${ }^{[6]}$. Previous studies differ on whether prenatal, postnatal or chronic depression symptoms exert the greatest influence on cognitive development ${ }^{[1]}$. While some of the variation in results may be accounted for by differences in assessment timing, other explanations may lie in the definitions of chronic depression applied (lasting from the first months postpartum to the first 2 years of the child's life), the period of follow-up, as well as control variables ${ }^{[7 ; 8]}$. A recent review of longitudinal studies found limited evidence for a small effect of prenatal and postnatal depression on cognitive and language development in school-aged children ${ }^{[8]}$. Other studies indicate that chronicity of depression, rather than timing, contributes to worse cognitive or language outcomes in the toddler and young child ${ }^{[3 ; 6 ; 9]}$. However, most investigations of the inter-relationships between chronic depression and child development have been conducted after childbirth, with only a few studies ${ }^{[10 ; 11]}$ collecting data prospectively from pregnancy onwards. Failure to account for maternal mood during pregnancy prevents from firmly concluding that the contribution of antenatal depression is less relevant for child cognitive development than its chronicity. Thus, a number of questions regarding the 
association between maternal mental health and child cognitive development remain unanswered, including the particular circumstances under which depression is associated with child outcomes. For instance, some of the adverse effects of maternal depression on cognitive development were only found in boys or in children from a lower socioeconomic background ${ }^{[4 ; 6]}$.

The aim of this study was to assess the association between maternal depressive symptoms and children's cognitive development at ages 5 to 6 . Importantly, we expand previous research by considering differing longitudinal trajectory groups of maternal depression from pregnancy onwards, which allows us to examine both timing and course of maternal depression on child IQ. In addition, we explored whether co-occurring risk factors modified the associations between maternal depression and children's cognitive outcomes. We hypothesized that the impact of maternal depressive symptom trajectories on children's cognitive outcomes would be greater in boys or in children from families with low income or parental educational level.

\section{Materials and Methods}

\section{$\underline{\text { Participants }}$}

The EDEN mother-child cohort was set up to assess the pre- and postnatal nutritional, social, and environmental determinants of infant and child development and health ${ }^{[12]}$. Pregnant women were recruited before 24 weeks of gestation from two maternity wards (Poitiers and Nancy University hospitals in France) between September 2003 and January 2006. Exclusion criteria were multiple pregnancies, a known history of diabetes, the inability to speak and read French or plans to move out of the study region in the following 3 years. Among 3758 eligible women invited to participate, $53 \%$ $(n=2002)$ were enrolled in the study and birth data were obtained from 1899 mother-infant pairs. During pregnancy and after birth (4, 8, 12, 24 months, 3, 4 and 5 years), socio-demographic and biomedical data on the mother and child were gathered a) from medical records, b) in face to face interviews with the mother and c) by mother's self-completed questionnaires. At the 5-year follow-up, data were available for $1255(66 \%)$ participating mothers and children, with complete data regarding 
the main variables of interest (i.e. IQ and maternal symptoms of depression) available for 1039 children. Attrition was highest in young mothers, those with low educational level and low income, of non-French origin, who did not live with the father of their child, as well as those who were depressed during pregnancy or in the postpartum period. Figure 1 shows the flow chart of the EDEN population from the pregnant mother's inclusion to the child's cognitive assessments. Written consent was obtained from the mother for herself at inclusion and for her newborn child after delivery. The EDEN study was approved by the Comité Consultatif de Protection des Personnes dans la Recherche Biomédicale (Ethics Committee, Kremlin Bicêtre Hospital) and by the Commission Nationale de 1'Informatique et des Libertés (National Committee for Processed Data and Freedom (CNIL)).

-- Insert figure 1 about here-

\section{$\underline{\text { Measures and procedures }}$}

\section{Maternal depressive symptom trajectories}

Maternal symptoms of depression in pregnancy and at 3 and 5 years follow-up were assessed using the Center for Epidemiological Studies Depression (CES-D) questionnaire ${ }^{[13]}$, a 20 -item questionnaire measuring the number of symptoms over the preceding week (range 0-60) with high reliability and validity ${ }^{[14]}$. Maternal symptoms of depression during the first year after the child's birth $(4,8$ and 12 months postpartum) were assessed using the Edinburgh Postnatal Depression Scale (EPDS), a 10-item questionnaire designed to detect postnatal depression ${ }^{[15]}$ (range 0-30). To identify trajectories of maternal depressive symptoms we needed to meaningfully combine the scores of both instruments, which have different possible symptom severity score ranges. Thus, the scores for each instrument were standardized by the sample mean and standard deviation for each time point to t-scores $(M=50$, $\mathrm{SD}=10$ ), which allowed us to study them jointly as continuous measures ${ }^{[16,17]}$.

Using the six scores available to us, we calculated trajectories of mothers' depressive symptoms using a semi-parametric mixture model (PROC TRAJ in SAS 9.3) ${ }^{[18]}$. To determine the optimal model of depression trajectories, we used statistical fit indices as well as the overall interpretability. As previous research had led us to expect to find 3 to 6 trajectory groups, models with 3-6 trajectories were estimated using a censored normal distribution. We used the Bayesian information Criteria (BIC) and 
entropy to identify the best-fitting model with the least number of trajectories ${ }^{[19]}$. As shown in Table 1, the BIC scores continued to improve from the three- group to the six-group model, and ranged from -24493.62 to -24326.91. Although the BIC score was somewhat better for the six-group model than for the five-group model (-24369.08), we adopted the latter since the six-group solution subdivided the sample into smaller groups (one additional group of 2.2\%) that did not improve the classification of subjects. Next, the model was refined by selecting the shape of each group's trajectory in a step-wise manner, comparing BIC scores for decreasingly less complex orders (i.e. cubic, linear, quadratic, linear, intercept only). To define a good model, the average posterior probabilities of trajectory membership should be at least equal to 0.7 for all groups. The average posterior probabilities of group membership were above 0.80 for all trajectories in the five-group model (range $0.81-0.95, \mathrm{M}=0.87$ ) and slightly superior to those for the six-group model (range $0.79-0.95, \mathrm{M}=0.85$ ).

Thus, five trajectory groups were identified: no symptoms $(62.2 \%, \mathrm{n}=645)$; persistent intermediate-level depressive symptoms $(24.7 \%, \mathrm{n}=257)$; persistent high-level depressive symptoms $(4.7 \%, \mathrm{n}=49)$; high symptoms in pregnancy only $(3.6 \%, \mathrm{n}=38)$; high symptoms in the child's preschool period only $(4.8 \%, \mathrm{n}=50)$ (Figure 2).

- Insert table 1 about here -

- Insert figure 2 about here-

\section{Child cognitive development}

Children's cognitive function was assessed by trained psychologists between ages 5 and 6 years (mean age 5.7 years), with the Wechsler Preschool and Primary Scale of Intelligence Third Edition (WPPSIIII) ${ }^{[20]}$. The core subtests (Information, Vocabulary, Word Reasoning, Block Design, Matrix Reasoning, Picture Concepts, and Coding) assess general cognitive abilities across several domains, from which three composite scores can be derived: Verbal IQ (VIQ), Performance IQ (PIQ), and FullScale IQ (FSIQ). Scores were age-normed in accordance with standard procedures with the observed distribution of IQ in the sample corresponding to an expected theoretical mean of 100 and standard deviation (SD) of 15 . 


\section{Covariates}

Covariates included in the multivariate analysis include maternal, child and family characteristics ascertained at study baseline unless indicated otherwise and associated $(\mathrm{p}<.10)$ with child cognitive development and maternal depressive symptoms. Maternal characteristics included: age at delivery, history of mental health problems (no vs. yes), any mental health treatment from pregnancy to 5 years later (no vs yes), anxiety in pregnancy (State-Trait Anxiety Inventory (STAI) ${ }^{[21]}$, maternal smoking and alcohol use during pregnancy (no vs. yes), social support (emotional or instrumental support from spouse or relevant others; no vs. yes), maternal pre-pregnancy body mass index (BMI) $\left(\mathrm{kg} / \mathrm{m}^{2}\right)$, total energy intake during pregnancy $(\mathrm{kJ})$, any breastfeeding duration (months) and an estimate of maternal cognitive stimulations (average of weekly frequencies for storytelling, singing and playing with the child, as reported by mothers at 3 years, range 1(never/rarely) to 5 (every day)). When the children were 5 years old, stimulation of the child at home was assessed by a psychologist using three subscales of the Home Observation for the Measurement of the Environment Scale: language stimulation, academic stimulation, and variety of experimentations ${ }^{[22,23]}$. Higher scores represent greater cognitive stimulation and emotional support.

Child characteristics included: child's sex (male vs. female), premature birth $(<37$ vs. $\geq 37$ weeks of gestation), birth weight (grams), birth order (firstborn no vs. yes), age at school entry (years) and bilingualism (no vs. yes). Family characteristics were: study center (Poitiers vs. Nancy), parental education (mean of maternal and paternal school years), family situation from pregnancy to the $5^{\text {th }}$ year assessment (parents living together vs. separated), low family income from pregnancy to the $5^{\text {th }}$ year assessment ( $<1500$ euros/month, category closest to the bottom quartile; no vs. yes), , domestic violence from pregnancy to the $5^{\text {th }}$ year assessment (no vs. yes), paternal substance abuse (no vs. yes), and family history of language problems (speech delays, difficulties in oral expression; no vs. yes).

\section{$\underline{\text { Statistical analyses }}$}

First, we compared characteristics of study participants across the five trajectories of maternal symptoms of depression using ANOVA and Chi-square tests. Second, we tested associations between maternal depression trajectories and each of the IQ outcomes (VIQ, PIQ and FSIQ) by means of linear 
regression analyses with the 'no depression' group serving as the reference category. Third, we used multivariable linear regression to assess associations between maternal depressive symptom trajectories and children's cognitive scores while controlling for previously listed covariates (model 2). Fourth, to account for the possible effect of concurrent maternal depression at age 5 on ratings of children's IQ, we calculated trajectories of maternal depression omitting the last data point, and repeated the analyses based on these modified trajectories model 3). Fifth, we examined possible interactions between maternal depressive symptoms and a) child sex and b) family socio-economic status as ascertained by family income and parental educational level with regard to children's cognitive outcomes. Rates of missing data on maternal, child and family characteristics ranged from $0.3 \%$ to $12.9 \%$ and were accounted for by using multiple imputations by fully conditional specification. Excluding individuals with missing data from our analyses did not alter the significance of our results. Analyses were conducted with SPSS version 20.

\section{Results}

Table 2 shows the sample's characteristics. Mothers with depressive symptoms were more likely to have experienced previous mental health problems, high levels of anxiety during pregnancy, and domestic violence, have a low family income and more often a birth before term. For the whole population, child mean verbal, performance and full scale IQ scores were, respectively $106.88 \pm 14.17$ (mean $\pm \mathrm{SD}$ ), $99.64 \pm 13.80$ and $103.35 \pm 13.51$. A small number of children $(n=6)$ had either very high or low scores, but as these cases did not have an undue influence on the model fit and we decided not to remove them from the analysis.

-- Insert table 2 about here --

Table 3 and Figure 3 displays associations between maternal depressive symptom trajectories and children's WPPSI-III scores at ages 5 to 6 . Overall, we observed a statistically significant association between maternal depression during pregnancy, persistent intermediate or high-level symptoms and children's cognitive development (Verbal, Performance and Full Scale IQ). After adjusting for covariates and concurrent maternal depression (models 2 and 3), only associations between persistent 
high-level symptoms of maternal depression and children's Verbal ( $b=--7.05$ [95\%CI -12.89; -1.20], $p=0.018)$, Performance $(b=-6.01$ [95\%CI -[-11.83; -.18], $p=0.043)$ and Full Scale IQ $(b=-6.70$ [95\%CI 12.24; -1.17-], $p=0.018$ ) remained statistically significant.

-- Insert table 3 about here -- -

-- Insert Figure 3 about here--

We found statistically significant interactions between maternal depressive symptom trajectories and children's sex for Performance IQ $(\mathrm{F}(4,758)=3.087, p=.015)$ and Full Scale IQ $(\mathrm{F}(4,755)=2.685$, $p=.030)$, but not Verbal IQ $(\mathrm{F}(4,758)=1.787, p=.129)$, with boys most likely to have low cognitive scores in case of persistent maternal depression. We found no evidence of an interaction between family socioeconomic position and maternal depression and children's cognitive outcomes.

\section{Discussion}

\section{Main findings}

This study is the first to use depressive symptom trajectories to explore the associations between maternal depression from pregnancy up to five years later and children's cognitive development at age 5 to 6 years. We found that chronicity rather than timing of maternal depression is important for children's cognitive development. In particular, compared to children of never depressed mothers, children of mothers who have persistently high levels of depressive symptoms show decreased IQ (6.7 points of IQ on average). This association appears to be stronger in boys than in girls.

\section{Patterns of association between maternal depression and children's IQ}

The current study used a semi parametric approach to identify a substantial (29.4\%) subgroup of mothers who experienced a pattern of chronic depression of either intermediate or high-level intensity beginning in pregnancy and lasting 5 years. Previous studies suggest that maternal depression of longer duration contributes to worse cognitive and language outcomes in toddlers and young children 
${ }^{[6 ; 9 ; 24]}$. To our knowledge, we are the first to directly compare heterogeneous groups of maternal depressive symptoms from pregnancy onwards for their impact on offspring's cognitive development. In our sample, children's mean IQ scores fell within the average range for all maternal depression groups. Nevertheless, Full scale IQ scores of children of mothers with persistently high-level symptoms of depression were on average 6.7 points (95\% confidence interval [CI] -12.24 to -1.17 points) lower than those of never depressed mothers. Persistent depressive symptoms remained associated with lower child IQ scores even after accounting for concurrent maternal depression, suggesting that chronic maternal depression influences child development over and above concomitant low maternal mood. While a 6.7 point difference in scores still appears to fall within an acceptable range, it is important to note that these children were growing up with chronically depressed mothers. Women in this group experience more depressive episodes throughout their child's development than those with less persistent trajectories of depression. Thereby the decrease in children's IQ which we observed at age 5.5 may deepen with time.

Although we found an independent association between prenatal depressive symptoms and children's IQ, this association disappeared after adjustment for confounding factors, particularly socioeconomic factors. These results are in line with prior studies ${ }^{[25]}$. Maternal depression during pregnancy has been suggested to influence the developing fetus by altering the intra-uterine environment and interfering with neurodevelopmental processes, which could result in atypical cognitive and behavioral development ${ }^{[26]}$. However, this association could also be due to shared predictors of prenatal maternal depression and child development, such as socioeconomic disadvantage ${ }^{[27,28]}$ or unhealthy behaviors (smoking, alcohol use). Further, we did not find evidence for a specific timing effect of maternal depression in the postnatal period. It may be that a significant portion of women with postpartum-onset depression remain depressed beyond the child's first year, which in our study would have lead them to be assigned to a group with persistent symptoms. Nevertheless, with a notable exception ${ }^{[29]}$, prior studies indicate that exposure to maternal depression in the period up to one year after birth does not exert an independent influence on the child's cognitive function $^{[7 ; 10]}$. 


\section{Mechanisms linking maternal depression to children's $I Q$}

Several mechanisms could explain the association between chronic maternal depression and children's cognitive abilities. First, common genetic factors could contribute both to maternal depression and children's cognitive development. However, it should be noted that, compared to environmental factors, the genetic influence on mental abilities in young children is relatively low and only gradually increases during childhood until adulthood ${ }^{[2]}$. In fact, the environment seems to explain a large portion of the variance for verbal, nonverbal and general cognitive abilities in early childhood ${ }^{[30]}$. Second, the association could result from residual confounding by factors that co-occur with maternal depression and adverse outcomes in children ${ }^{[9]}$. However, given the number of covariates included in our analyses, this is unlikely the main explanation of our findings. Third, chronic maternal depression could influence the child's cognitive development through maladaptive parenting behaviors. Previous studies indicate that depressed mothers are less likely to provide a stable and predictable daily routine ${ }^{[3]}$, to propose stimulating objects and books, or engage in role-play, singing, playing, reading and telling stories ${ }^{[5 ; 31]}$. Such parenting behaviors may impede children's ability to reach developmental milestones in the cognitive and socio-emotional domains ${ }^{[11]}$. Importantly, in France most children start preschool at the age of 3 and at the time cognitive outcome data in our study were collected most participating children were in $1^{\text {st }}$ grade of elementary school; thus our findings suggest that maternal mental health influences children's cognitive development even in a context where children are stimulated in a formal setting. Fourth, depressed mothers have been found to use longer utterances, less repetition, more negative affect, fewer explanations, suggestions, and questions, and fewer references to their infants' behavior ${ }^{[4 ; 32]}$. Early experiences with insensitive maternal interactions and insecure mother-child attachment appear to be predictive of impaired cognitive functioning ${ }^{[33]}$.

In stratified analyses we found that the association between maternal depression and children's IQ was especially strong in boys, which is consistent with some prior studies ${ }^{[6]}$. Compared to girls, boys may have to put more effort in interacting with a chronically depressed mother, which leaves them less time for cognitively stimulating activities ${ }^{[4]}$. Nonetheless, it has also been observed that boys and girls somewhat differ in terms of cognitive development and these results may reflect normal developmental patterns ${ }^{[34]}$. As scores were not significantly different for boys and girls in the overall 
sample, this further strengthens our interpretation that the observed gender differences are specifically due to young boys' difficulty to adapt to maternal depression. Additional research is needed to further elucidate whether boys are more likely to experience adverse outcomes such as very low IQ $(<70)$ or neurodevelopmental disorders following persistent maternal depression. Regarding family socioeconomic position, we did not find evidence that parental education level or low family income moderated the association between maternal depression and child development. While it has consistently been reported that disadvantaged mothers are disproportionately likely to experience psychological problems such as depression ${ }^{[35}$, only a limited number of studies have examined the combined effect of maternal depression and socioeconomic status on children's cognitive functioning ${ }^{[7]}$. Results are mixed, with certain studies reporting that maternal depression and social disadvantage affect children's cognition independently ${ }^{[11 ; 25]}$, whereas other studies suggest that the effect of maternal depression is particularly pronounced when co-occurring with contextual risks ${ }^{[24]}$. As socially disadvantaged parents generally have fewer resources with which to engage their children in cognitively stimulating interactions, both the family economic situation and maternal mental health could be regarded as parental resources that have the potential to affect children's development by creating a less rich home environment ${ }^{[31]}$.

\section{Strengths and limitations}

Our research has a number of strengths, including a) repeated assessments of maternal depressive symptoms from pregnancy onwards, b) the use of a validated measure of children's cognitive development administered by trained psychologists, and c) the measurement of a wide range of potential confounding variables characterizing children and their families. However, we also need to acknowledge limitations. First, like many epidemiological cohorts, the EDEN study is characterized by selective non-response among socially disadvantaged women who are at high risk of depression. Compared with a national perinatal survey on a representative sample of French women, the EDEN study was similar in age and proportion of unmarried couples but included a larger proportion of women with university level education (53 vs. $43 \%$ ). This might lead to an underestimation of the link between maternal depression and child IQ scores in our study. Further, the sample includes relatively 
low numbers of individuals from ethnic minority groups. The present results will need replication with more ethnically diverse samples.

Second, the trajectory analysis to determine depressive symptom trajectories may lead to the identification of groups containing a small proportion of the sample. While this is consistent with other studies using this approach, it is possible that between-group differences were not detected due to lower statistical power in the smaller subgroups. Additionally, including binary covariates might also have led to a decrease in power and the ability to observe significant effects. Third, maternal depressive symptoms were self-reported, using two different measures. However, both the CES-D and the EPDS have previously been validated and we were able to study the entire depression spectrum rather than diagnoses, which may be a closer estimate of variations in symptomatology at the population level. Finally, we did not account for maternal IQ, which could confound the association between maternal depression and children's cognitive development. Nonetheless, we accounted for parental educational and income level and frequency of mother-child activities, which probably capture part of the variability associated with maternal IQ. Also, previous research ${ }^{[29]}$ showed that children exposed to maternal postnatal depression had lower cognitive abilities, even after controlling for maternal IQ, which further strengthens our belief that our findings are not spurious.

\section{Conclusion}

While it is reassuring that in our community sample maternal depressive symptoms at one point in time are not associated with children's cognitive development, children of mothers who have persistently elevated symptom levels may require special attention. Disparities in learning and cognitive skills at the pre-school ages are amplified when children enter the school system, which may eventually translate into lower educational attainment ${ }^{[31]}$. Lower childhood IQ may have an etiological role in the development of adult psychiatric disorders ${ }^{[36]}$.

Yet, despite the recognized prevalence of maternal depression in the general population, health care providers often do not make the connection between a mother's positive screening for depression and the risk to a child's well-being. Equally, children's cognitive development and maternal depression are often not considered together. As maternal mental health represents one of the earliest modifiable 
influences on children's development, mental health care professionals as well as pediatricians should be made aware of the impact of maternal mental health on children's IQ to assure timely screening and follow-up. Increasing evidence suggests that psychological treatment of depressed mothers can attenuate the risks for their children ${ }^{[37]}$. It is very possible that successful treatment of their depression allows mothers to improve their parenting behaviors, which then enhance the quality of their relationship with their children and thereby result in more positive child outcomes ${ }^{[38]}$. These mediating mechanisms need to be further explored in future studies and might guide the development of evidence-based prevention and treatment interventions for mothers as well as their children. In a previous study we reported that a history of mental health problems, work stress during pregnancy and prenatal anxiety symptoms put women at high risk of later persistent depressive symptoms ${ }^{[39]}$. Women who present these characteristics may require specific monitoring. Identification of mothers at risk for chronic depression during the prenatal period and in the first years of life may provide an early opportunity to reduce the burden of ill health and reduced life chances for the next generation. 


\section{Acknowledgements:}

We are grateful to the participating families, the midwife research assistants (Lorraine Douhaud, Sophie Bedel, Brigitte Lortholary, Sophie Gabriel, Muriel Rogeon, and Monique Malinbaum) for data collection, the psychologists (Marie-Claire Cona and Marielle Paquinet) and the data entry operators (Patricia Lavoine, Josiane Sahuquillo and Ginette Debotte).

The EDEN study was funded by Fondation pour la Recherche Médicale (FRM), French Ministry of Research: IFR Program, INSERM Human Nutrition National Research Program, and Diabetes National Research Program (through a collaboration with the French Association of Diabetic Patients (AFD)), French Ministry of Health, French Agency for Environment Security (AFSSET), French National Institute for Population Health Surveillance (InVS), Paris-Sud University, French National Institute for Health Education (INPES), Nestlé, Mutuelle Générale de l'Education Nationale (MGEN), French speaking association for the study of diabetes and metabolism (ALFEDIAM), National Agency for Research (ANR nonthematic programme), National Institute for Research in Public Health (IRESP: TGIR Cohorte Santé 2008 programme).

This study was funded by the French National Research Agency (ANR, Program on Social Determinants of Health), the Fondation pour la Recherche en Psychiatrie et Santé Mentale (FRPSM) and the National Institute for Research in Public Health (IRESP: General Project Call 2014). The funders had no role in the design and conduct of the study; in the collection, management, analysis, and interpretation of the data; and preparation, review, or approval of the manuscript. 


\section{References}

1. Kingston D, McDonald S, Austin MP et al. Association between prenatal and postnatal psychological distress and toddler cognitive development: A systematic review. PloS One 2015;10(5):e0126929.

2. Tucker-Drob EM, Briley DA. Continuity of genetic and environmental influences on cognition across the life span: A meta-analysis of longitudinal twin and adoption studies. Psychol Bull 2014;140(4):949-979.

3. Conners-Burrow NA, Bokony P, Whiteside-Mansell L et al. Low-level depressive symptoms reduce maternal support for child cognitive development. J Ped Health Care 2014;28(5):40412.

4. Grace SL, Evindar A, Stewart DE. The effect of postpartum depression on child cognitive development and behavior: A review and critical analysis of the literature. Arch Womens Ment Health 2003;6(4):263-74.

5. Sohr-Preston SL, Scaramella LV. Implications of timing of maternal depressive symptoms for early cognitive and language development. Clin Child Fam Psychol Rev 2006;9(1):65-83.

6. Azak S. Maternal depression and sex differences shape the infants' trajectories of cognitive development. Infant Behav Dev 2012;35(4):803-14.

7. Piteo AM, Yelland LN, Makrides M. Does maternal depression predict developmental outcome in 18 month old infants? Early Hum Dev 2012;88(8):651-655.

8. Kingston D, Tough S. Prenatal and postnatal maternal mental health and school-age child development: A systematic review. Matern Child Health J 2013.

9. Cornish AM, McMahon CA, Ungerer JA et al. Postnatal depression and infant cognitive and motor development in the second postnatal year: The impact of depression chronicity and infant gender. Infant Behav Dev 2005;28(4):407-417.

10. Evans J, Melotti R, Heron J et al. The timing of maternal depressive symptoms and child cognitive development: A longitudinal study. J Child Psychol Psychiatry 2012;53(6):632-640. 
11. Jensen SK, Dumontheil I, Barker ED. Developmental inter-relations between early maternal depression, contextual risks, and interpersonal stress, and their effect on later child cognitive functioning. Depress Anxiety 2014;31(7):599-607.

12. Heude B, Forhan A, Slama R et al. Cohort profile: The Eden mother-child cohort on the prenatal and early postnatal determinants of child health and development. Int J Epidemiol 2015 .

13. Radloff LS. The CES-D scale: A self-report depression scale for research in the general population. Appl Psychol Meas 1977;1(3):385-401.

14. Joiner TE, Walker RL, Pettit JW et al. Evidence-based assessment of depression in adults. Psychol Assess 2005;17(3):267-277.

15. Cox JL, Holden JM, Sagovsky R. Detection of postnatal depression. Development of the 10item Edinburgh postnatal depression scale. Br J Psychiatry 1987;150:782-6.

16. Norman, GR. and Streiner, DL. Biostatistics: The Bare Essentials, 3e. People's Medical Publishing House -USA. 2008

17. Willett JB, Singer JD, Martin NC. The design and analysis of longitudinal studies of development and psychopathology in context: statistical models and methodological recommendations. Dev Psychopathol 1998;10(2): 395-426.

18. Nagin DS, Odgers CL (2010) Group-based trajectory modeling in clinical research. Annu Rev Clin Psychol 6: 109-138

19. Nagin D. Group-based modeling of development. Cambridge, MA: Harvard University Press. 2005.

20. Wechsler D. Wppsi-iii administration and scoring manual. San Antonio, TX: The Psychological Corporation. 2002.

21. Spielberger CD, Gorsuch RL, Lushene PR et al. Manual for the state-trait anxiety inventory (form y). Palo Alto: Consulting Psychologists Press, Inc. 1983.

22. Frankenburg WK, Coons CE. Home screening questionnaire: Its validity in assessing home environment. J Pediatr 1986;108(4):624-626. 
23. Caldwell BM, Bradley RH. Home observation for measurement of the environment:

Administration manual. Tempe, AZ: Family \& Human Dynamics Research Institute, Arizona State University. 2003.

24. Kurstjens S, Wolke D. Effects of maternal depression on cognitive development of children over the first 7 years of life. J Child Psychol Psychiatry 2001;42(5):623-36.

25. Tse AC, Rich-Edwards JW, Rifas-Shiman SL et al. Association of maternal prenatal depressive symptoms with child cognition at age 3 years. Paediatr Perinat Epidemiol 2010;24(3):232-40.

26. Barker ED, Kirkham N, Ng J et al. Prenatal maternal depression symptoms and nutrition, and child cognitive function. Br J Psychiatry 2013;203:417-21.

27. Tong S, Baghurst P, Vimpani G et al. Socioeconomic position, maternal IQ, home environment, and cognitive development. J Pediatr 2007;151(3):284-8, 288 e1.

28. Eriksen HL, Kesmodel US, Underbjerg M et al. Predictors of intelligence at the age of 5: Family, pregnancy and birth characteristics, postnatal influences, and postnatal growth. PloS One 2013;8(11):e79200.

29. Hay DF, Pawlby S, Waters CS et al. Antepartum and postpartum exposure to maternal depression: Different effects on different adolescent outcomes. J Child Psychol Psychiatry 2008;49(10):1079-1088.

30. Spinath FM, Ronald A, Harlaar N et al. Phenotypic 'g' early in life: On the etiology of general cognitive ability in a large population sample of twin children aged 2 to 4 years. Intelligence 2003;31:195-210.

31. Kiernan KE, Huerta MC. Economic deprivation, maternal depression, parenting and children's cognitive and emotional development in early childhood. Br J Sociol 2008;59(4):783-806.

32. Keim SA, Daniels JL, Dole N et al. A prospective study of maternal anxiety, perceived stress, and depressive symptoms in relation to infant cognitive development. Early Hum Dev 2011;87(5):373-80.

33. Ding $\mathrm{YH}, \mathrm{Xu} \mathrm{X}$, Wang $\mathrm{ZY}$ et al. The relation of infant attachment to attachment and cognitive and behavioural outcomes in early childhood. Early Hum Dev 2014;90(9):459-64. 
34. Gur RC, Richard J, Calkins ME et al. Age, group and sex differences in performance on a computerized neurocognitive battery in children age 8-21. Neuropsychology 2012;26(2):25165.

35. Goyal D, Gay C, Lee KA. How much does low socioeconomic status increase the risk of prenatal and postpartum depressive symptoms in first-time mothers? Womens Health Issues 2010;20(2):96-104.

36. Batty GD, Mortensen EL, Osler M. Childhood IQ in relation to later psychiatric disorder: Evidence from a Danish birth cohort study. Br J Psych 2005;187:180-1.

37. Cuijpers P, Weitz E, Karyotaki E et al. The effects of psychological treatment of maternal depression on children and parental functioning: A meta-analysis. Eur Child Adolesc Psychiatry 2015;24(2):237-245.

38. Pilowsky DJ, Wickramaratne P, Poh E et al. Psychopathology and functioning among children of treated depressed fathers and mothers. J Affective Dis 2014;164:107-11.

39. Van Der Waerden J, Galera C, Saurel-Cubizolles MJ et al. Predictors of persistent maternal depression trajectories in early childhood: Results from the eden mother-child cohort study in france. Psychol Med 2015; 45, 1999-2012. 


\begin{tabular}{|c|c|c|c|c|}
\hline \multicolumn{5}{|c|}{ Table 1- Fit indices for latent classes } \\
\hline Classes & BIC & AIC & Entropy & Class sizes based on estimated model (\%) \\
\hline 1 & -25376.84 & -25363.18 & 1.00 & 100 \\
\hline 2 & -24659.48 & -24632.17 & 0.94 & $74.6 / 25.4$ \\
\hline 3 & -24493.62 & -24452.66 & 0.92 & $63.8 / 31.5 / 4.7$ \\
\hline 4 & -24413.21 & -24358.60 & 0.89 & $63.0 / 28.0 / 4.4 / 4.6$ \\
\hline 5 & -24369.08 & -24300.81 & 0.87 & $62.2 / 24.7 / 4.7 / 3.6 / 4.8$ \\
\hline 6 & -24326.91 & -24244.98 & 0.85 & $51.5 / 29.5 / 6.0 / 4.5 / 6.3 / 2.2$ \\
\hline $\begin{array}{l}\text { BIC; Baye } \\
\text { AIC; Akai } \\
\text { Entropy ; r }\end{array}$ & $\begin{array}{l}\text { nformation } \\
\text { cormation cri } \\
\text { Ire of classif }\end{array}$ & $\begin{array}{l}\text { on- lower va } \\
\text { lower valu } \\
\text {; ranges } 0.0\end{array}$ & $\begin{array}{l}\text { are better } \\
\text { better } \\
0, \text { with va }\end{array}$ & loser to 1.00 being best \\
\hline
\end{tabular}




\begin{tabular}{|c|c|c|c|c|c|c|c|}
\hline \multicolumn{8}{|c|}{ Table 2 Mother, family and child characteristics of EDEN cohort study participants $(n=1039)$} \\
\hline & $\begin{array}{l}\text { Overall sample } \\
\quad(n=1039)\end{array}$ & $\begin{array}{l}\text { No symptoms } \\
\quad(n=645)\end{array}$ & $\begin{array}{l}\text { Symptoms in } \\
\text { pregnancy only } \\
(n=38)\end{array}$ & $\begin{array}{l}\text { Symptoms during } \\
\text { the child's } \\
\text { preschool period } \\
(n=50)\end{array}$ & $\begin{array}{c}\text { Persistent } \\
\text { intermediate- level } \\
\text { symptoms } \\
(n=257)\end{array}$ & $\begin{array}{l}\text { Persistent } \\
\text { high-level } \\
\text { symptoms } \\
(n=49)\end{array}$ & \\
\hline & $\begin{array}{c}N(\%) \\
\text { Mean }(\text { sd })\end{array}$ & $\begin{array}{c}N(\%) \\
\text { Mean }(\text { sd })\end{array}$ & $\begin{array}{c}N(\%) \\
\text { Mean }(\text { sd })\end{array}$ & $\begin{array}{c}N(\%) \\
\text { Mean }(\text { sd })\end{array}$ & $\begin{array}{c}N(\%) \\
\text { Mean }(\text { sd })\end{array}$ & $\begin{array}{c}N(\%) \\
\text { Mean }(\text { sd })\end{array}$ & $\begin{array}{l}\text { Test statistic } \\
P \text { value } \\
\end{array}$ \\
\hline \multicolumn{8}{|l|}{ Maternal characteristics } \\
\hline $\begin{array}{l}\text { History of mental health } \\
\text { problems }\end{array}$ & & & & & & & $\begin{array}{c}\mathrm{X}^{2}(4, \mathrm{~N}=1039)=74.48 \\
p<.001\end{array}$ \\
\hline Yes & $157(15.1 \%)$ & $59(9.1 \%)^{\mathrm{a}}$ & $11(28.9 \%)$ & $11(22.0 \%)$ & $52(20.0 \%)$ & $24(49.0 \%)^{b}$ & \\
\hline \multicolumn{8}{|l|}{ Mental health treatment } \\
\hline Yes & $286(27.5 \%)$ & $125(19.4 \%)^{\mathrm{a}}$ & $19(50.0 \%)$ & $21(42.0 \%)$ & $91(35.4 \%)^{b}$ & $30(61.2 \%)^{c}$ & $\begin{array}{c}\mathrm{X}^{2}(4, \mathrm{~N}=1039)=72.22 \\
p<.001\end{array}$ \\
\hline $\begin{array}{l}\text { Smoking during } \\
\text { pregnancy }\end{array}$ & & & & & & & $\begin{array}{c}\mathrm{X}^{2}(4, \mathrm{~N}=1034)=8.83 \\
p=.065\end{array}$ \\
\hline Yes & $230(22.2 \%)$ & $126(19.7 \%)$ & $13(34.2 \%)$ & $15(30.0 \%)$ & $65(25.4 \%)$ & $11(22.4 \%)$ & \\
\hline $\begin{array}{l}\text { Alcohol use during } \\
\text { pregnancy }\end{array}$ & & & & & & & $\begin{array}{c}\mathrm{X}^{2}(4, \mathrm{~N}=993)=7.89 \\
p=.096\end{array}$ \\
\hline Yes & $285(28.7 \%)$ & $167(26.8 \%)$ & $9(24.3 \%)$ & $21(43.8 \%)$ & $76(31.7 \%)$ & $12(26.1 \%)$ & \\
\hline $\begin{array}{l}\text { Experience of domestic } \\
\text { violence }\end{array}$ & & & & & & & $\begin{array}{c}\mathrm{X}^{2}(4, \mathrm{~N}=1018)=51.65 \\
p<.001\end{array}$ \\
\hline Yes & $58(5.7 \%)$ & $20(3.2 \%)^{\mathrm{a}}$ & $3(8.1 \%)$ & $6(12.2 \%)$ & $16(6.4 \%)^{b}$ & $13(26.5 \%)^{\mathrm{c}}$ & \\
\hline Social support & & & & & & & $\begin{array}{c}\mathrm{X}^{2}(4, \mathrm{~N}=1030)=13.36 \\
p=.010\end{array}$ \\
\hline No & $28(2.7 \%)$ & $13(2.0 \%)$ & $4(11.1 \%)^{\mathrm{a}}$ & $2(4.1 \%)$ & $6(2.3 \%)$ & $3(6.1 \%)$ & \\
\hline $\begin{array}{l}\text { Maternal anxiety (STAI) } \\
\text { in pregnancy }\end{array}$ & $9.97(9.63)$ & $6.77(6.84)$ & $24.45(14.71)$ & $13.04(9.39)$ & $12.61(8.97)$ & $23.76(12.11)$ & $\begin{array}{c}\mathrm{F}(4,1036)=96,23 \\
p<.001\end{array}$ \\
\hline $\begin{array}{l}\text { Pre pregnancy BMI } \\
\left(\mathrm{kg} / \mathrm{m}^{2}\right)\end{array}$ & $23.46(4.62)$ & $23.16(4.31)^{\mathrm{a}}$ & $24.68(4.92)^{b}$ & $24.21(4.75)$ & $23.66(4.87)$ & $24.66(6.33)^{c}$ & $\begin{array}{c}\mathrm{F}(4,1038)=2.61 \\
p=034\end{array}$ \\
\hline $\begin{array}{l}\text { Age at the child's birth } \\
\text { (years) }\end{array}$ & $30.21(4.76)$ & $30.16(4.63)$ & $31.55(4.92)$ & $31.02(4.47)$ & $29.91(4.99)$ & $30.49(5.17)$ & $\begin{array}{c}\mathrm{F}(4,1038)=1.44 \\
p=.220\end{array}$ \\
\hline
\end{tabular}




\begin{tabular}{|c|c|c|c|c|c|c|c|}
\hline during pregnancy $(\mathrm{Kj})$ & & & $(2760.85)$ & $(2993.40)$ & $(3234.10)$ & $(3584.04)^{\mathrm{a}}$ & $p=.005$ \\
\hline $\begin{array}{l}\text { Breastfeeding duration } \\
\text { (months) }\end{array}$ & $3.33(4.10)$ & $3.56(4.26)$ & $2.19(2.51)$ & $3.24(3.52)$ & $3.01(3.95)$ & $2.92(4.25)$ & $\begin{array}{c}\mathrm{F}(4,1038)=1.77 \\
p=.133\end{array}$ \\
\hline $\begin{array}{l}\text { Frequency of maternal } \\
\text { stimulations age } 3\end{array}$ & $4.36(.57)$ & $4.38(.56)$ & $4.18(.76)$ & $4.41(.49)$ & $4.36(.56)$ & $4.19(.61)$ & $\begin{array}{c}\mathrm{F}(4,944)=2.13 \\
p=.076\end{array}$ \\
\hline HOME score age 5 & $17.32(2.16)$ & $17.30(2.23)$ & $17.44(2.56)$ & $16.94(2.49)$ & $17.42(2.15)$ & $16.41(2.28)^{\mathrm{a}}$ & $\begin{array}{c}\mathrm{F}(4,1038)=2.43 \\
p=.046\end{array}$ \\
\hline \multicolumn{8}{|l|}{ Family characteristics } \\
\hline Nancy & $450(43.3 \%)$ & $292(45.3 \%)$ & $12(31.6 \%)$ & $29(58.0 \%)^{\mathrm{a}}$ & $97(37.7 \%)^{b}$ & $20(40.8 \%)$ & \\
\hline Family income & & & & & & & $\begin{array}{c}\mathrm{X}^{2}(4, \mathrm{~N}=1020)=33.25 \\
p<.001\end{array}$ \\
\hline$<1500 € / \mathrm{mo}$ & $318(31.2 \%)$ & $167(26.3 \%)^{\mathrm{a}}$ & $17(45.9 \%)$ & $25(50.0 \%)$ & $82(32.7 \%)$ & $27(56.2 \%)$ & \\
\hline Family situation & & & & & & & $\begin{array}{c}\mathrm{X}^{2}(4, \mathrm{~N}=1029)=17.63 \\
p=.001\end{array}$ \\
\hline Separated & $151(14.7 \%)$ & $75(11.7 \%)^{\mathrm{a}}$ & $8(21.1 \%)$ & $14(28.0 \%)^{b}$ & $42(16.6 \%)$ & $12(25.0 \%)^{b}$ & \\
\hline Yes & $53(5.1 \%)$ & $30(4.7 \%)$ & $2(5.3 \%)$ & $2(4.0 \%)$ & $17(6.6 \%)$ & $2(4.1 \%)$ & \\
\hline $\begin{array}{l}\text { Parental educational level } \\
\text { (years) }\end{array}$ & $13.54(2.28)$ & $13.76(2.28)^{\mathrm{a}}$ & $12.68(1.97)$ & $13.00(2.28)$ & $13.29(2.23)$ & $13.09(2.46)$ & $\begin{array}{c}\mathrm{F}(4,1038)=4.76 \\
p=.001\end{array}$ \\
\hline \multicolumn{8}{|l|}{ Child characteristics } \\
\hline Sex & & & & & & & $\begin{array}{c}\mathrm{X}^{2}(4, \mathrm{~N}=1039)=3.08 \\
p=.545\end{array}$ \\
\hline Male & $550(52.9 \%)$ & $350(45.7 \%)$ & $19(50.0 \%)$ & $24(52.0 \%)$ & $136(47.1 \%)$ & $21(57.1 \%)$ & \\
\hline Preterm birth (<37 weeks) & & & & & & & $\begin{array}{c}\mathrm{X}^{2}(4, \mathrm{~N}=1039)=12.57 \\
p=.014\end{array}$ \\
\hline Yes & $59(5.7 \%)$ & $29(4.5 \%)^{\mathrm{a}}$ & $3(7.9 \%)$ & $6(12.0 \%)$ & $14(5.4 \%)$ & $7(14.3 \%)^{b}$ & \\
\hline Birth order & & & & & & & $\begin{array}{c}\mathrm{X}^{2}(4, \mathrm{~N}=1039)=7.29 \\
p=.121\end{array}$ \\
\hline Firstborn & $475(45.7 \%)$ & $305(47.3 \%)$ & $13(34.2 \%)$ & $18(36.0 \%)$ & $122(47.5 \%)$ & $17(34.7 \%)$ & \\
\hline Bilingualism & & & & & & & $\begin{array}{c}\mathrm{X}^{2}(4, \mathrm{~N}=1039)=9.33 \\
p=.053\end{array}$ \\
\hline
\end{tabular}




\begin{tabular}{|c|c|c|c|c|c|c|c|}
\hline Birth weight (grams) & $3287.66(512.76)$ & $3289.39(492.41)$ & 3161.97 (711.86) & $3191.40(540.03)$ & $3332.43(512.45)$ & $3265.31(557.12)$ & $\begin{array}{c}\mathrm{F}(4,1038)=1.52 \\
p=.192\end{array}$ \\
\hline $\begin{array}{l}\text { Age at school entry } \\
\text { (years) }\end{array}$ & $3.48(.64)$ & $3.48(.63)$ & $3.53(.65)$ & $3.46(.58)$ & $3.50(.66)$ & $3.43(.65)$ & $\begin{array}{c}\mathrm{F}(4,1038)=0.19 \\
p=.943\end{array}$ \\
\hline \multicolumn{8}{|l|}{$\begin{array}{l}\text { Children's WPSSI-III } \\
\text { scores age } 5 \text { to } 6\end{array}$} \\
\hline Verbal IQ & $106.88(14.17)$ & $107.64(13.71)$ & $102.58(13.77)$ & $107.90(14.97)$ & $106.55(14.38)$ & $101.00(16.78)^{\mathrm{a}}$ & $\begin{array}{c}\mathrm{F}(4,1038)=3.58 \\
p=.007\end{array}$ \\
\hline Performance IQ & $99.64(13.80)$ & $100.58(13.23)^{\mathrm{a}}$ & $94.73(13.45)$ & $101.50(11.76)^{b}$ & $98.30(14.79)$ & $96.10(16.31)$ & $\begin{array}{c}\mathrm{F}(4,1037)=3.59 \\
p=.006\end{array}$ \\
\hline Full scale IQ & $103.35(13.51)$ & $104.38(12.63)$ & $96.92(13.71)^{\mathrm{a}}$ & $104.82(13.12)$ & $102.51(14.39)$ & $97.67(17.18)^{b}$ & $\begin{array}{c}\mathrm{F}(4,1031)=5.68 \\
p<.001\end{array}$ \\
\hline \multicolumn{8}{|l|}{$\begin{array}{l}\text { Unadjusted maternal } \\
\text { depressive symptom } \\
\text { scores }\end{array}$} \\
\hline In pregnancy & $11.08(7.85)$ & $8.04(5.10)$ & $32.24(8.72)$ & $11.98(5.47)$ & $13.23(5.91)$ & $22.82(8.36)$ & $\begin{array}{c}\mathrm{F}(4,1033)=236.64 \\
p<.001\end{array}$ \\
\hline $\begin{array}{l}8 \text { months after the child's } \\
\text { birth }\end{array}$ & $4.72(4.62)$ & $2.31(2.37)$ & $7.39(5.01)$ & $6.06(3.18)$ & $8.55(4.17)$ & $13.51(5.05)$ & $\begin{array}{c}\mathrm{F}(4,1002)=268.75 \\
\text { p. } 001\end{array}$ \\
\hline $\begin{array}{l}12 \text { months after the } \\
\text { child's birth }\end{array}$ & $4.37(4.56)$ & $2.06(2.26)$ & $4.63(3.73)$ & $5.07(3.87)$ & $8.45(4.16)$ & $13.20(5.01)$ & $\begin{array}{c}\mathrm{F}(4,975)=275.52 \\
p<.001\end{array}$ \\
\hline $\begin{array}{l}3 \text { years after the child's } \\
\text { birth }\end{array}$ & $9.63(8.06)$ & $6.57(5.159)$ & $9.33(6.81)$ & $14.67(7.94)$ & $12.86(7.51)$ & $28.95(8.62)$ & $\begin{array}{c}\mathrm{F}(4,978)=163.78 \\
p<.001\end{array}$ \\
\hline $\begin{array}{l}5 \text { years after the child's } \\
\text { birth }\end{array}$ & $9.40(8.16)$ & $6.07(4.57)$ & $10.05(5.81)$ & $29.86(5.40)$ & $10.90(5.78)$ & $24.27(10.29)$ & $\begin{array}{c}\mathrm{F}(4,1021)=377.11 \\
p<.001\end{array}$ \\
\hline
\end{tabular}




\begin{tabular}{|c|c|c|c|c|c|c|}
\hline & \multicolumn{6}{|c|}{ Children's WPPSI-III scores } \\
\hline & \multicolumn{2}{|c|}{ WPPSI-III Verbal IQ } & \multicolumn{2}{|c|}{ WPPSI-III Performance IQ } & \multicolumn{2}{|c|}{ WPPSI-III Full scale IQ } \\
\hline & $B(95 \% C I)$ & $p$ & $B(95 \% C I)$ & $p$ & $B(95 \% C I)$ & $p$ \\
\hline \multicolumn{7}{|l|}{1 Unadjusted model } \\
\hline No symptoms & [ref] & & {$[\mathrm{ref}]$} & & [ref] & \\
\hline High symptoms in pregnancy only & $-5.06[-9.68--0.44]$ & .032 & $-5.85[-10.41--1.30]$ & .012 & $-7.46[-11.90--3.02]$ & .001 \\
\hline High symptoms in preschool period only & $0.26[-3.80-4.32]$ & .899 & $0.92[-3.04-4.87]$ & .649 & $0.44[-3.46-4.33]$ & .825 \\
\hline Persistent intermediate-level symptoms & $-1.09[-3.13-.96]$ & .297 & $-2.34[-4.32--0.35]$ & .021 & $-1.87[-3.81-0.08]$ & .060 \\
\hline Persistent high-level symptoms & $-6.64[-10.74--2.54]$ & .002 & $-4.48[-8.47--0.49]$ & .028 & $-6.70[-10.60--2.81]$ & .001 \\
\hline \multicolumn{7}{|l|}{2 Adjusted model ${ }^{1}$} \\
\hline No symptoms & [ref] & & [ref] & & [ref] & \\
\hline High symptoms in pregnancy only & $1,34[-4.67-7.36]$ & .662 & $.25[-5.81-6.32]$ & .935 & $1.38[-4.37-7.13]$ &. .638 \\
\hline High symptoms in preschool period only & $2.78[-1.76-7.31]$ & .230 & $1.52[-3.05-6.10]$ & .513 & $2.18[-222-6.58]$ &. .331 \\
\hline Persistent intermediate-level symptoms & $-1.16[-3.50-1.18]$ & .333 & $-2.35[-4.71-.02]$ & .050 & $-1.61[-385-.39]$ &. .162 \\
\hline Persistent high-level symptoms & $-6.13[-11.36--.89]$ & .022 & $-4.63[-9.91--.64]$ & .085 & $-5.76[-10.76--.75]$ & .024 \\
\hline \multicolumn{7}{|l|}{3 Adjusted model $^{2}$} \\
\hline No symptoms & [ref] & & [ref] & & [ref] & \\
\hline High symptoms in pregnancy only & $--.46[-7.94-7.01]$ & .902 & $-4.27[-11.73-3.17]$ & .260 & $-2.43[-9.50-4.63]$ & .499 \\
\hline High symptoms in preschool period only & $-.13[-4.81-4.54]$ & .955 & $-3.80[-8.46-.86]$ & .110 & $-1.79[-6.21-2.63]$ & .427 \\
\hline Persistent intermediate-level symptoms & $.06[-2.74-2.86]$ & .966 & $-1.17[-3.96-1.62]$ & .411 & $-.20[-2.86-2.46]$ & .883 \\
\hline Persistent high-level symptoms & $-7.05[-12.89--1.20]$ & .018 & $-6.01[-11.83--.18]$ & .043 & $-6.70[-12.24--1.17]$ & .018 \\
\hline \multicolumn{7}{|c|}{$\begin{array}{l}\text { Adjusted for: age at birth, history of mental health problems, anxiety in pregnancy, substance use during pregnancy, mental health treatment, pre pregnancy BMI, total } \\
\text { energy intake during pregnancy, breastfeeding duration, frequency of maternal stimulations, HOME score, parental educational level, family income, family situation, } \\
\text { domestic violence, social support, family history of language problems, study center, child sex, preterm birth, birth weight, birth order, age at school entry, bilingualism } \\
{ }^{2} \text { Adjusted for all covariates in model } 2 \text { and concurrent maternal depression at age } 5 \\
\text { WPPSI: Wechsler Preschool and Primary Scale of Intelligence; IQ: Intelligence Quotient; B: Regression coefficient; CI: Confidence Interval; ref: reference }\end{array}$} \\
\hline
\end{tabular}




\section{Figure 1 Study flow-chart}

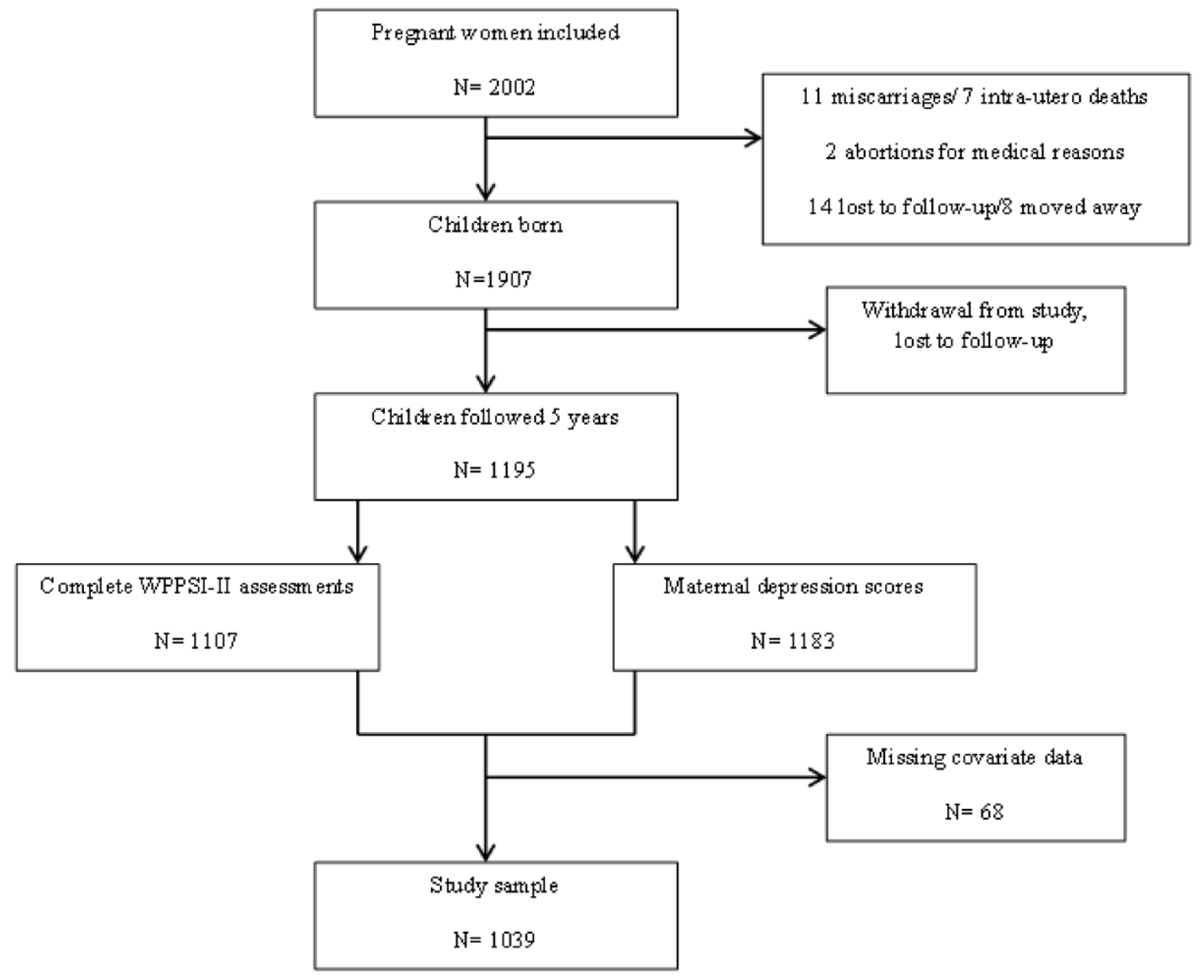


Figure 2 Trajectories of maternal symptoms of depression by child's age in months in the EDEN cohort study

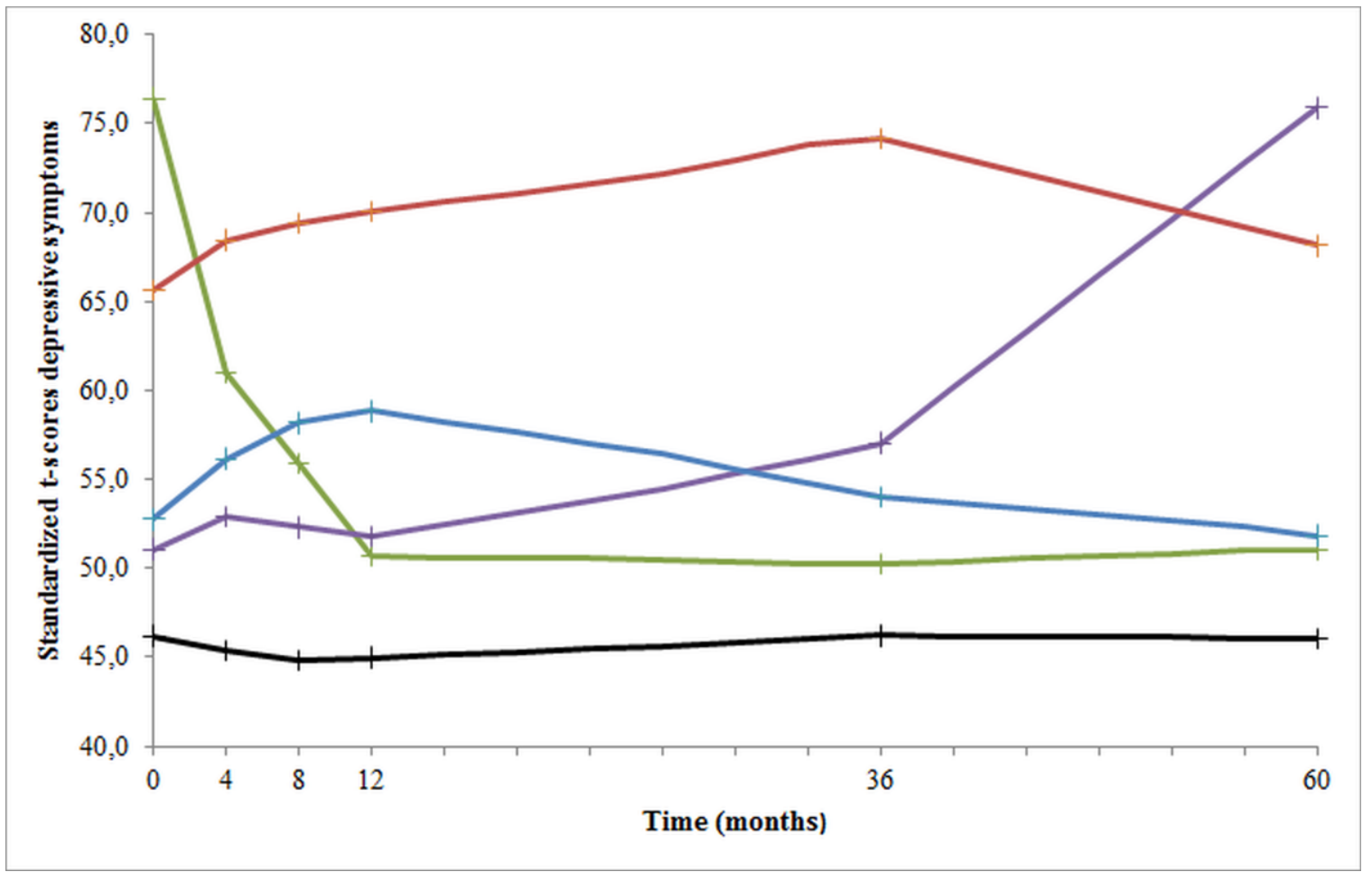

Figure legend:

No symptoms
High symptoms in pregnancy only
High symptoms in preschool period only
Persistent intermediate-level depressive symptoms
Persistent high level depressive symptoms 
Figure 3 Mean and range for children's VIQ, PIQ and FSIQ scores according to the different maternal depression trajectories

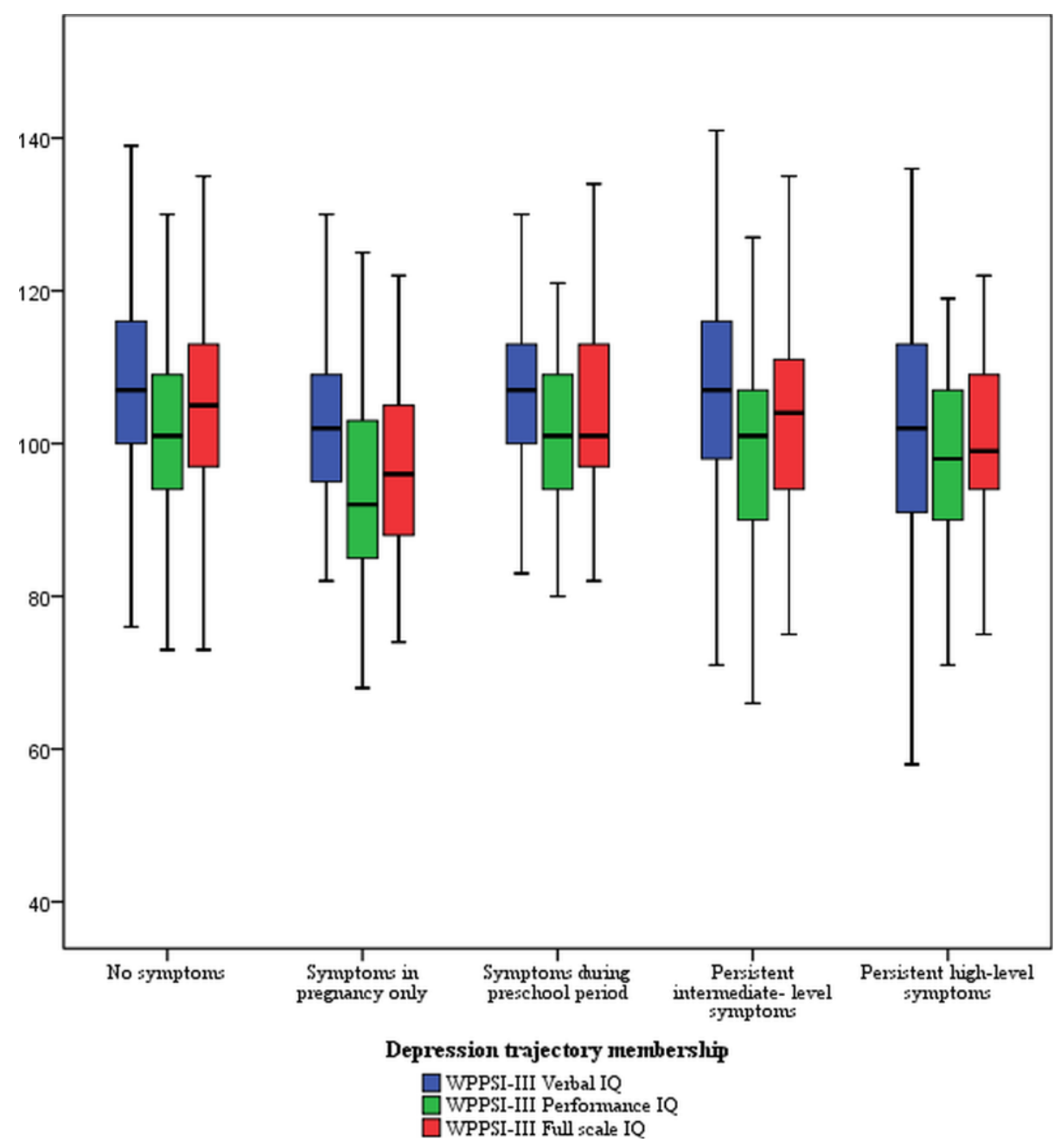

Figure legend:

WPPSI-III Verbal IQ

WPPSI-III Performance IQ

WPPSI-III Full Scale IQ 